\title{
A Comprehensive Research of the Air-void Defect of Concrete-filled Steel Tube
}

\author{
Chao Guo', Zhengran Lu* \\ ${ }^{1}$ School of Civil Engineering, Shenyang Jianzhu University, Middle Hunnan Road, Shenyang 110168, China \\ * Corresponding author, e-mail: luzhengran@sjzu.edu.cn
}

Received: 24 October 2019, Accepted: 28 December 2020, Published online: 08 January 2021

\begin{abstract}
Welded spiral steel tubes are adapted for use in a majority of the large-diameter concrete-filled steel tube (CFST) arch bridges due to technical as well as economic reasons. However, the welding temperature and other factors during the process of manufacturing of steel tube, initially result in a reduced spiral-welded seam (SWS) strength. Moreover, with the pumping of concrete into a steel tube, numerous deformities of the likes of laitance coating and air-voids occurred inevitably, particularly with the lack of air-entraining agent in China almost 20 years ago. This work makes use of ultrasonic scanning field experience to investigate the capacity of bearing within a repaired and reconditioned CFST arch bridge rib having defects such as air-void and reduced SWS strength under negligible compression of eccentric axial by carrying out its finite element model analysis of group. The outcome reveals that CFST bearing capacity is only minimally affected by the SWS strength as compared to concrete air-void, which can be ignored. The effect of air-voids and the nonlinear behavior of the constituents on the CFST behavior have also been probed into. The impact of the air-void on the rib capacity of bearing was investigated by conducting parametric studies. To conclude, we proposed a new index defining the ultimate strength of the rib for the defect, and presented a rather simple blueprint to determine the influence of air-void on the final strength of the arch bridge rib of CFST.
\end{abstract}

Keywords

spiral-welded seam, concrete-filled steel tube, air-void, finite element method, arch bridge

\section{Introduction}

Quite a few concrete-filled steel tubes (CFST) arch bridges, being used for several years, have manifested part defects. These defects occur in the steel tube or are concrete column imperfections that arise due to initial manufacturing or during their service life [1]. Pumping of concrete into the steel tube leads to the inevitable occurrence of laitance coating and air-voids, when there wasn't any provision for airentraining in China. In the harsh environments, the air-void undergoes expansion, shortening the bridge service life and eventually leading to the eventual collapse of the bridge.

The Chang-Qing Hun River bridge was originally built in 1997 and is represented in Fig. 1. The major portion of the bridge encompasses a stretch of $120+140+120 \mathrm{~m}$. A through-type CFST arch rib framework comprised the bridge bearing type. The cross-section of arch is $1.8 \mathrm{~m}$ in width and $2.4 \mathrm{~m}$ in height. Four tubes, each having a diameter of $720 \mathrm{~mm}$ comprise each rib whereas the spiral-welded tube (SWT) has a thickness equal to $10 \mathrm{~mm}$.
The adjoining edges of a steel plate that bends helically are welded to fabricate SWTs. Nevertheless, compared to the base metal, SWTs manifest a reduced welded seam strength, and thereby, are considered to have a single defect. Concrete-filled SWT columns have been subjected to several tests, considering long and short column behavior, to ascertain the extent to which the current guidelines are applicable for evaluating their strength and types of failures $[2,3]$.

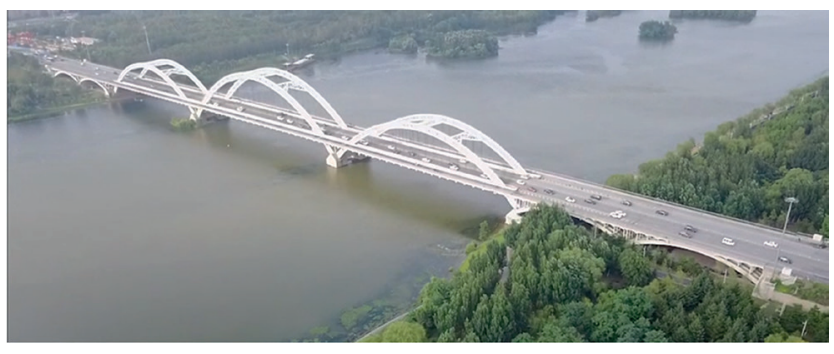

Fig. 1 Chang-Qing Hun River bridge 
There was only $70 \%$ penetration of the spiral-welded seam (SWS). Therefore, as illustrated in Fig. 2, a steel band $10 \mathrm{~mm}$ thick and $80 \mathrm{~mm}$ wide was put in place to strengthen the welded joint of the bridge in the 2012 maintenance event.

The concrete originally employed for use in the mentioned bridge was ordinary concrete [4]. To fill in the tubes of the bridge, C50 concrete was chosen. Nevertheless, due to the construction technology being limited in that era, the concrete within the tube got segregated. In the light of the core-taking test carried out on the location, near the inner tube wall and within a range of $7 \mathrm{~cm}$, the strength of concrete was found to be $\mathrm{C} 20$, as illustrated in Fig. 3 due to the presence of the laitance coating and air-voids in the core of concrete.

In civil engineering, non-destructive ultrasonic testing technology is being extensively in use for inspecting the defects lying in the structure of concrete. Recently, a good number of indoor assessments on CFST defects

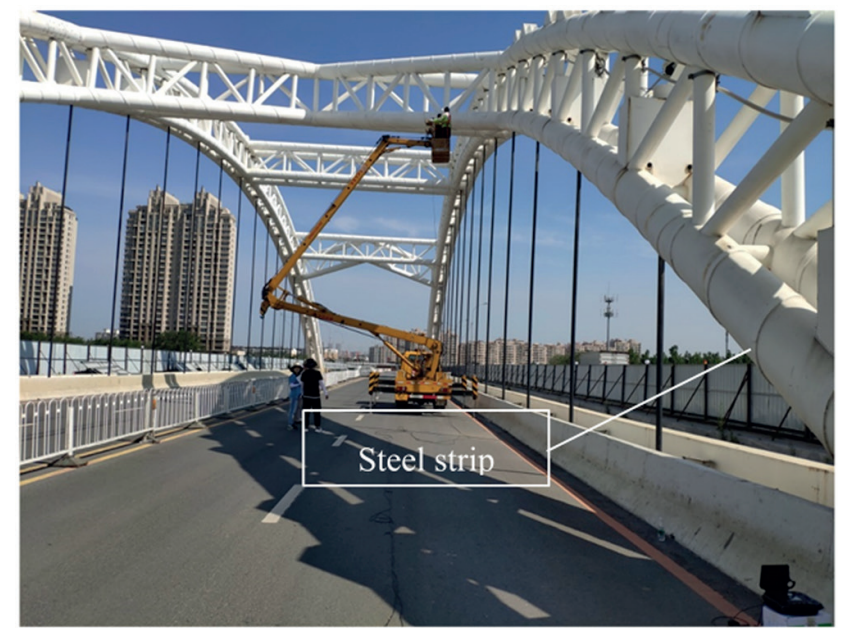

Fig. 2 Details of CFST arch

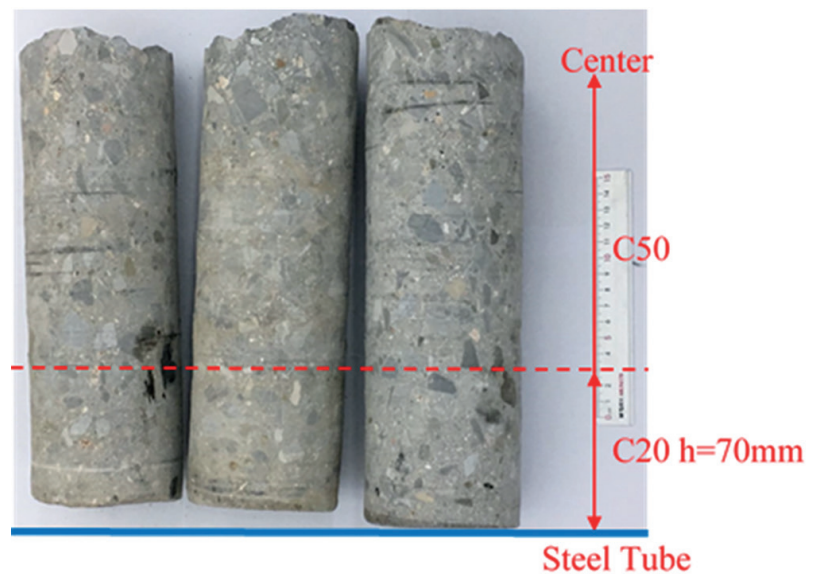

Fig. 3 Concrete segregating specimen in tube have proven the reliability of its test results [5-8]. In the vast majority of cases, detection of the imperfections of the CFST is sufficient to furnish enough data for assessing defects in the arch rib of CFST. The results of this research illustrated in Fig. 4 have been obtained by making use of MIRA A1040, a scanning imager based on the principle of ultrasonic three-dimensional (3D) scanning and produced via ACSYS of Russia. The area of interface gap and the total area of tube have a ratio of $3.6 \%$ to $30.5 \%$ approximately, whereas the signal anomaly region lies at a depth of around 0 to $70 \mathrm{~mm}$.

Finite element (FE) analysis is also an important technique utilized in CFST research, in addition to ultrasonic testing. For CFST columns, an elastic-to-plastic FEM was constructed by Ellobody and Young [9] Han et al. [10], Schneider [11], Hu et al. [12], and, having a square or circular section. A nonlinear FEM was carried out by Ellobody and Young [13], Hassanein [14], and Tao et al. [15, 16] on CFST long or short columns. A nonlinear FEM for compre-

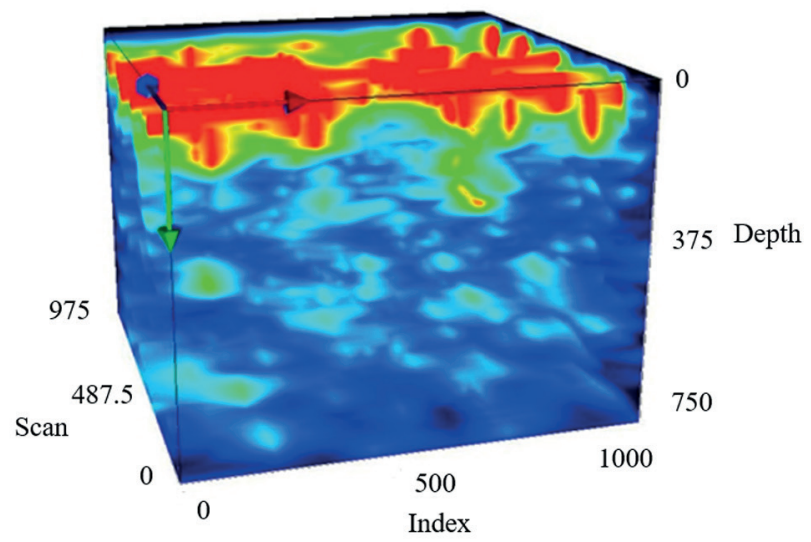

(a)

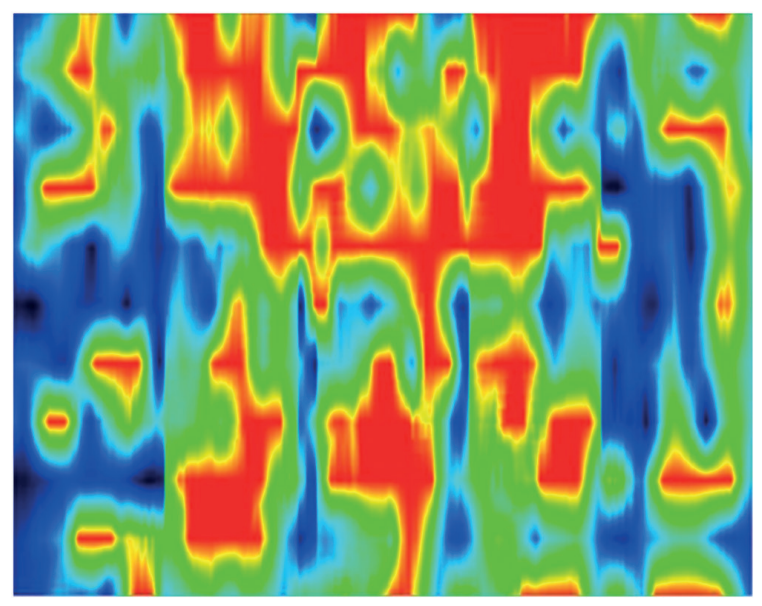

(b)

Fig. 4 Ultrasonic scanning imagery of CFST, (a) 3D section scanning imagery, (b) Plane scanning imagery 
hensively analyzing elliptically sectioned CFST columns was established by Dai and Lam [17] and $\mathrm{Hu}$ and $\mathrm{Su}$ [18] and Huang et al. [19], made use of ABAQUS to analyze CFST columns behavior nonlinearly. Jaishi and Ren [20] utilized two-node beam elements by making use of ANSYS to establish a linear FEM for a through arch bridge.

The primary focus of most of the aforementioned investigations has been seamless small-diameter or straightwelded CFSTs, omitting the impact of the concrete air-void defects and the strength of SWS on their bearing potential. Nevertheless, the above defects will inevitably affect actual CFSTs, in particular large-diameter CFST arch bridges. So far, Han et al. [21, 22], Huang et al. [23], Liu et al. [24], and Liao et al. $[25,26]$ have extensively examined the single-factor defects of CFST ribs. They established FEMs for analytical investigations after performing a series of experiments for the estimation of the cap and circumferential gaps, where the section gap ratio is the key calculating parameter. In the light of these facts, an assessment of the impact of concrete ratio of air-void $(\alpha)$ as well as SWS on the bearing potential of CFST was complemented by a group of FEM in this work.

For an air-void containing CFST rib, as depicted in Fig. 5:

$\alpha=\frac{V_{\text {air-void }}}{V_{c}}$,

where the volume corresponding to the air-void lying within the concrete core is represented by $V_{\text {air-void }}$ is, as shown in Fig. $5 ; V_{c}$ refers to the cylinder volume which can vibrate the concrete without causing it to compact.

The objective of the on-going investigation is to carry out a sequence of nonlinear FEM of 3-m length rib element of a CFST arch bridge, corresponding to the distance of the two vertical braces, with the concrete core fringes having air-void and composite defect due to reduced SWS strength under the influence of eccentric axial compression. The main process steps of this work are outlined below; firstly, a 3D elastic-to-plastic FEM with no-defect is created on ABAQUS, which includes the nonlinear material constitutive model only. Secondly, CFST ribs

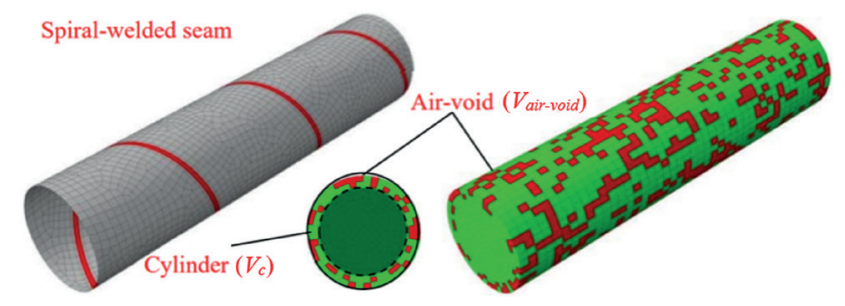

Fig. 5 Mesh of CFST composite defects with only one fault such as the air void or decreased SWS strength, detected in the light of the ultrasonic detection data of the arched rib of the River Bridge CFST of ChangQing Hun, were investigated for their bearing capacity making use of a python stochastic FE analysis program developed on ABAQUS. Thirdly, a prediction regarding the strength of the rib of the CFST arch bridge is made after performing a composite defect study on the above stochastic FE analysis program.

\section{FE analysis}

\subsection{Basic conditions}

For the FE analysis, ABAQUS, the general finite element software, was utilized. 4-node reduced integration shell element (S4R) was employed to stimulate SWT. 8-node hexahedral elements (C3D8) having a total of three translation degrees of freedom (DoFs) at individual nodes were employed for modeling the concrete in the core. In an attempt to receive reliable data, identification of an appropriate mesh density was done by carrying out a mesh optimization design. The CFST rib as a 3D mesh with composite defects is illustrated in Fig. 5.

A new Python script process was developed to study the internal air-void defects of concrete by re-editing the ABAQUS.inp files of the CFST rib FEM with no defects. Following the given probability distribution function, one could randomly select the elements of the corresponding volume fraction defined by the air-void ratio $(\alpha)$ in the particular area, followed by categorizing it into the corresponding sets, using the material parameters of the defects, in order to attain appropriate defects simulation in FE analysis, finally.

The typical zone identified by CFST ultrasound comprises the defect elements and mainly lies within a $70 \mathrm{~mm}$ range from the center to the fringe of the concrete core. Python random software is used to observe the constituents in this FEM zone, randomly extracting respectively $10 \%, 20 \%$, and $30 \%$ elements as pores, in accordance with the space normal distribution, so the sampling level of various air-void faults can be realized.

To actualize the eccentric axial loading boundary circumstance, the top-most point of reference of a rib was subjected to enforced displacement. With the arch rib of the bridge being a compression element having a minimal irregularity, the eccentricity was ascertained as $\mathrm{D} / 6$, as per the combination of load. An analytical rigid body was used to constrain the CFST ends. 


\subsection{Material characteristics and constitutive models}

\subsubsection{Steel}

The arched rib of the River Bridge of Chang-Qing Hun which had been repaired was utilized to furnish the concrete and steel tube samples employed in this FEM assessment.

In the case of steel tubes, different researchers have used a variety of stress $(\sigma)$-strain $(\varepsilon)$ models, for instance, the linear elastic perfectly plastic model with multi-curve hardening [27]. At strain values corresponding to general structural requirements $(\varepsilon<0.005)$, very little strain-hardening is manifested by steel. Various $\sigma-\varepsilon$ relations of steel cast an impact on CFST rib in terms of the loadstrain curves at the desired strains within the arch bridge. Specifically, for the $150 \mathrm{~m}$ spans of the arch bridge structure examined as a part of this work, a little strain will subsequently cause alterations in the rigidity of the bridge. Tao et al. [28] proposed a $\sigma-\varepsilon$ model for the steel tube with a validity strength which ranges from 200 to $800 \mathrm{MPa}$. As per the tensile measurement of the sample of steel tube, $\sigma-\varepsilon$ relation of the steel-based piping functions according to a trilinear material property model within the arch rib belonging to this bridge, as illustrated in Fig. 6 .

At the starting point of the $\sigma-\varepsilon$ line, the elastic modulus is represented by $E_{s}$; the ultimate strength of the steel tube in the arch rib of the CFST for the under consideration case is referred to as $f_{u}$; the yield strain is $\varepsilon_{y}$, $\varepsilon_{y}=f_{y} / E_{s}$; the strain at the location of strain-hardening is represented by $\varepsilon_{p}$; the ultimate strain which corresponds to the ultimate strength is $\varepsilon_{u}$. The expression put forth by Tao et al. [29] was employed for distinguishing $f_{u}$ from $f_{y}$ in circumstances where no tensile collapse was encountered via the steel.

Table 1 presents the key attributes of the steel tube in the aforementioned circumstance.

\subsubsection{Concrete}

In the case of this bridge, the respective values of the cylinder compressive strength $f_{c}{ }^{\prime}$ Poisson's ratio $\mu_{c}$, and the strain $\varepsilon_{c}{ }^{\prime}$ corresponding to a specimen of concrete subjected to uniaxial compressive stress and having a diameter equivalent to $100 \mathrm{~mm}$ are $33 \mathrm{MPa}, 0.21$, and 0.0033 .

$E_{c}$ was calculated as $2.7 \times 10^{4} \mathrm{MPa}$ by adopting the empirical Eq. (2) as per the recommendation in ACI318 [30], the value of $f_{c}{ }^{\prime}$ being in the MPa's units.

$E_{c}=4700 \sqrt{f_{c}^{\prime}}$

Papanikolaou and Kappos [31] collected test data based on which the value of $f_{b c} / f_{c}{ }^{\prime}$ was found to 1.12 using the Eq. (3) proposed by them: $f_{b c} / f_{c}^{\prime}=1.5\left(f_{c}^{\prime}\right)^{-0.075}$

Herein, the initial equibiaxial compressive yield stress is denoted by $f_{b c}$. When a circular confining pressure is subjected upon the core concrete, the uniaxial compressive yield strength $f_{c}{ }^{\prime}$ and corresponding strain $\varepsilon_{c}{ }^{\prime}$ as shown in Fig. 7 are notably high in comparison to the concrete that is unconfined. Mander et al. [32, 33] estimated the correlation among and and among and.

Han and An [34] proposed a comparable $\sigma-\varepsilon$ model in the light of the model originally presented by Mander, to replicate the plastic behavior of the concrete within the CFSTs core under the influence of pressure or compression $y=2 x-x^{2}$

$y=\left\{\begin{array}{ll}1+q \cdot\left(x^{0.1 \xi}-1\right) & (\xi \geq 1.12) \\ \frac{x}{\beta \cdot(x-1)^{2}+x} & (\xi<1.12)\end{array}\right\}(x>1)$,

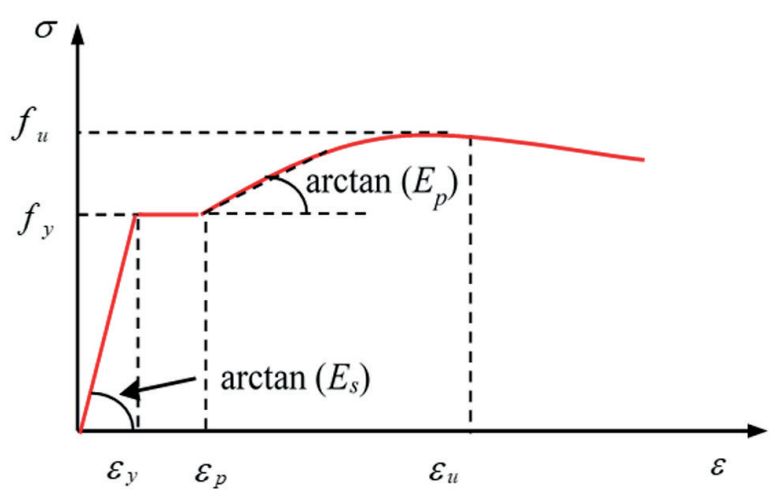

Fig. 6 Model for steel tube properties

Table 1 Key attributes of the steel tube

\begin{tabular}{cccccccc}
\hline $\begin{array}{c}t \\
\mathrm{~mm}\end{array}$ & $\begin{array}{c}D \\
\mathrm{~mm}\end{array}$ & $\begin{array}{c}E_{s} \\
\mathrm{MPa}\end{array}$ & $\mu_{s}$ & $\begin{array}{c}f_{y} \\
\mathrm{MPa}\end{array}$ & $\begin{array}{c}f_{u} \\
\mathrm{MPa}\end{array}$ & $\varepsilon_{s}$ & $\varepsilon_{u}$ \\
\hline 10 & 700 & $2.0 \times 10^{5}$ & 0.32 & 345 & 400 & 0.00192 & 0.179 \\
\hline
\end{tabular}

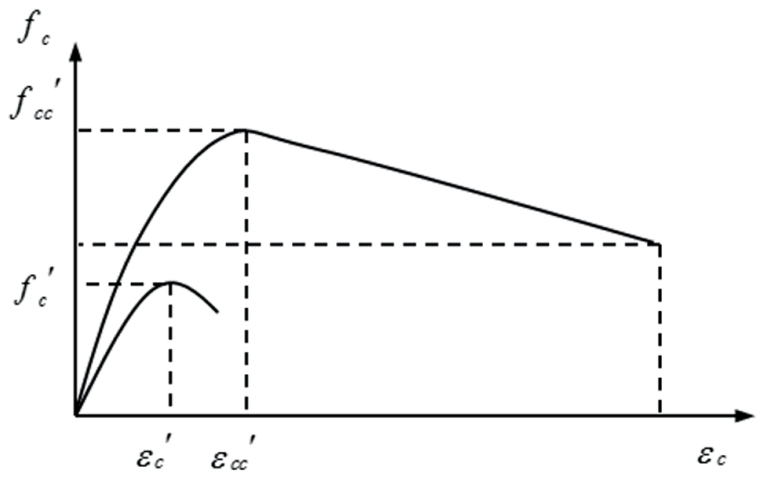

Fig. 7 Stress-strain curve 
$\sigma_{0}=\left(1+\left(-0.054 \xi^{2}+0.4 \xi\right)\left(\frac{24}{f_{c}^{\prime}}\right)^{0.45}\right) f_{c}^{\prime}$,

$\varepsilon_{0}=\varepsilon_{c c}+\left(1400+800\left(\frac{f_{c}^{\prime}}{24}-1\right)\right) \xi^{0.2}$,

$q=\frac{\xi^{0.745}}{2+\xi}$,

$\beta=\left(2.36 \times 10^{-5}\right)^{\left(0.25+(\xi-0.5)^{7}\right)} f_{c}^{\prime 2} \cdot 3.51 \times 10^{-4}$,

in which $x=\varepsilon / \varepsilon_{0}, y=\sigma / \sigma_{0}$; the confinement factor $\xi$ is denoted by

$\xi=\frac{A_{s} f_{y}}{A_{c} f_{c}^{\prime}}$,

where the area of cross-sectional corresponding to the concrete based core and SWTs are sequentially represented by $A_{c}$ and $A_{s}$.

The data obtained as a result of the experiments presented in [35] suggest that the concrete confined within the interior of the CFST having only circumferential gap as a single defect was fractured once it approached the ultimate strength, without being confined by the outer SWTs. Hence, unconfined concrete is best described by the compressive $\sigma-\varepsilon$ model put forth by Samani and Attard [36].

To model the concrete yield surface, a linear DruckerPrager yield criteria $G$ (Fig. 8) is employed, and is represented by the following expression

$G=q-p \tan \psi-d=0$,

where in

$$
\begin{aligned}
& p=-\left(\sigma_{1}+\sigma_{2}+\sigma_{3}\right) / 3 \\
& d=\left(1-\frac{\tan \psi}{3}\right) f_{c c}^{\prime} \\
& q=\frac{\sqrt{3 J_{2}}}{2}\left[1+\frac{1}{K}-\left(1-\frac{1}{K}\right)\left(\frac{r}{\sqrt{3 J_{2}}}\right)^{3}\right] \\
& r=\left[\frac{9}{2}\left(S_{1}^{3}+S_{2}^{3}+S_{3}^{3}\right)\right]^{1 / 3}
\end{aligned}
$$

in which the primary stress deviators are denoted by $S_{1}, S_{2}$, and $S_{3}$. The most important parameter utilized to estimate the yield surface of the concrete plasticity stress space is the fraction relationship of the second stress invariant on the tensile meridian to that on the compressive meridian $K$. As per the reports of Tao et al. [15], and Yu et al. [37, 38] $K$ can be determined in this study as 0.846 using the following Eq. (16):

$$
\begin{aligned}
& K=\frac{5.5}{5+2\left(f_{c}^{\prime}\right)^{0.075}}, \\
& \psi=\left\{\begin{array}{l}
56.3(1-\xi) \\
6.672 e^{\frac{7.4}{4.64+\xi}}
\end{array}\right.
\end{aligned}
$$

whereas $\xi=0.42$ within the arch rib of this CFST bridge.

\subsubsection{SWTs-core concrete interface}

An increment in the normal contact interaction will cause a continuous rise in the shear stress $\left(\tau_{c r i t}\right)$ on the junction among the SWT and core concrete until it surpasses the bond strength of surface $\left(\tau_{\text {bond }}\right)$.The $\tau_{\text {crit }}$ value is given by the following expression:

$\tau_{\text {crit }}=u \cdot p \geq \tau_{\text {bond }}$.

The value of $u$ the coefficient of friction is considered to be equal to 0.6 in this work [29], and

$\tau_{\text {bond }}=2.314-0.0195 \times(D / t)$.

The value of the typical pressure stress $\left(p_{n}\right)$ determines the tangential frictional stress $\left(\tau_{\text {fric }}\right)$, and the following expression can be used to represent it.

$\tau_{\text {fric }}=u \cdot p_{n}$

\section{Verification of FEM}

The typically measured curves were compared with the projected eccentric axial load $(N)$ against axial strain $(\varepsilon)$ curves. The ultimate limit states attained from the assessment were compared with the projected ones. The rib bearing capacity is decisively affected by the air-void rate in a CFST rib having an air-void defect. There has been no research

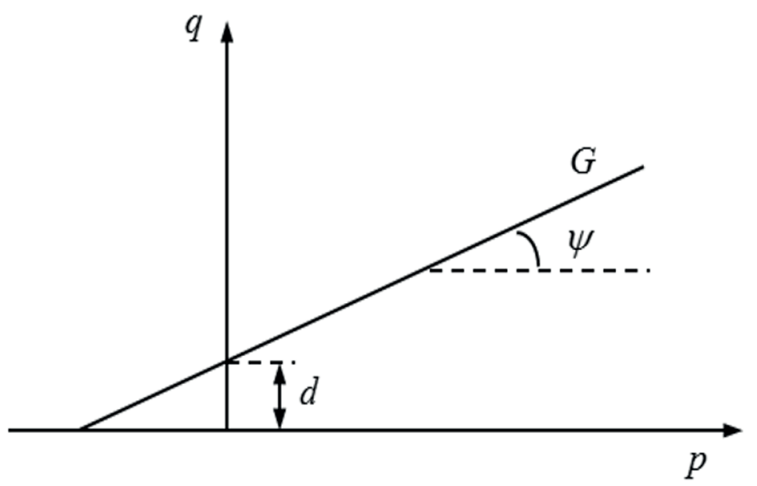

Fig. 8 Drucker-Prager criterion 
in terms of SWS strength defect so far. Accordingly, the following sections are based on an analysis of the composite deformities of the CFST columns with air-voids well as a decreased SWS strength.

\subsection{Analyzing the CFST rib in the presence or absence of SWS defect}

The sectional dimensions of the analytical columns are $D \times t=720 \times 10 \mathrm{~mm}$, and concrete strength of $f_{c}{ }^{\prime}=41 \mathrm{MPa}$ corresponding to the theoretically estimated strength of the Chang-Qing Hun River bridge framework.

\subsection{1 $N-\varepsilon$ curves of CFST rib in the presence or absence of SWS defect}

The SWS strength $(S)$ was $50 \%, 70 \%$, and $100 \%$, respectively, of desirable strength, equivalent in strength to the parent material. The length $L$ was $300 \mathrm{~mm}$ and the screwpitch was $0.95 \mathrm{~m}$. The analysis was first focused on the empty steel tube (EST), followed by the analysis of CFST rib, as shown in Fig. 9, which precisely draws comparative scrutiny of the $N-\varepsilon$ graphs of the EST in the presence and absence of an SWS fault. It is evident from Fig. 9(a) that in the presence or absence of an SWS deformity, the $N$ of the EST manifested a strain-softening potential until the axial strain $(\varepsilon=0.03)$ reaches a maximum after the yield strength was attained. Nevertheless, an EST strength loss of $2.6 \%$ and $11.2 \%$, respectively was caused by a $30 \%$ and $50 \%$ reduction in strength, due to the SWS deformity, which additionally led to a diminution of the strain-hardening potential. Hence, it is safe to conclude that the reduced strength contribution is primarily responsible for the strength diminution of the EST with an SWS defect.

Under different SWS defect conditions, the $N-\varepsilon$ curves of the CFST rib more or less match with each other as evident in Fig. 9(b). Thus, it can be safely deduced that the CFST bearing potential is practically not impacted the strength reduction of the EST having an SWS deformity or in circumstances when there are no defects in the internal concrete.

A comparison of the characteristic devastated modes of the EST rib is shown in Fig. 10. On the compression side of the EST, localized fold-like buckling of the SWS-S was found to take place in the situation where SWS-S was lower in comparison to the parent material. With the reduction in the SWS-S, this phenomenon became increasingly obvious. EST rib shows different failure modes. When the SWS-S is equal to or close to that of the parent material, local buckling failure occurs at the far end of the pipe;

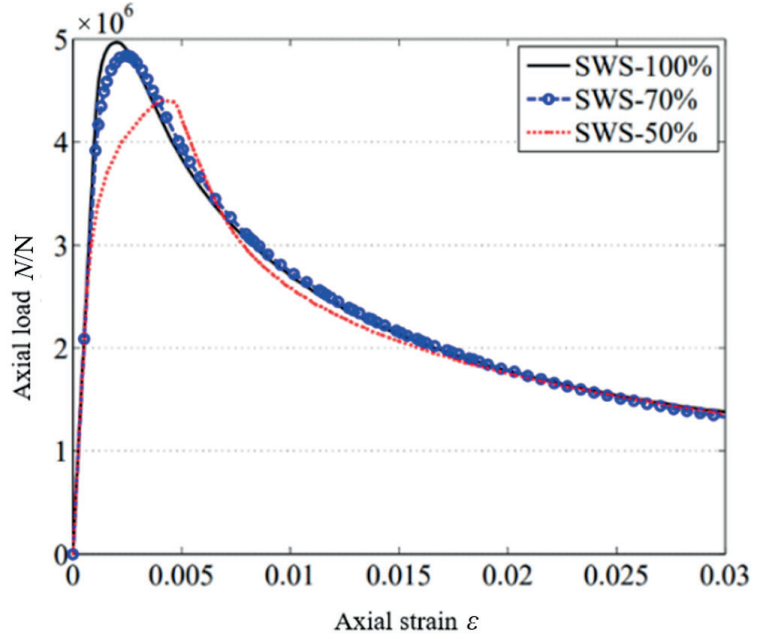

(a)

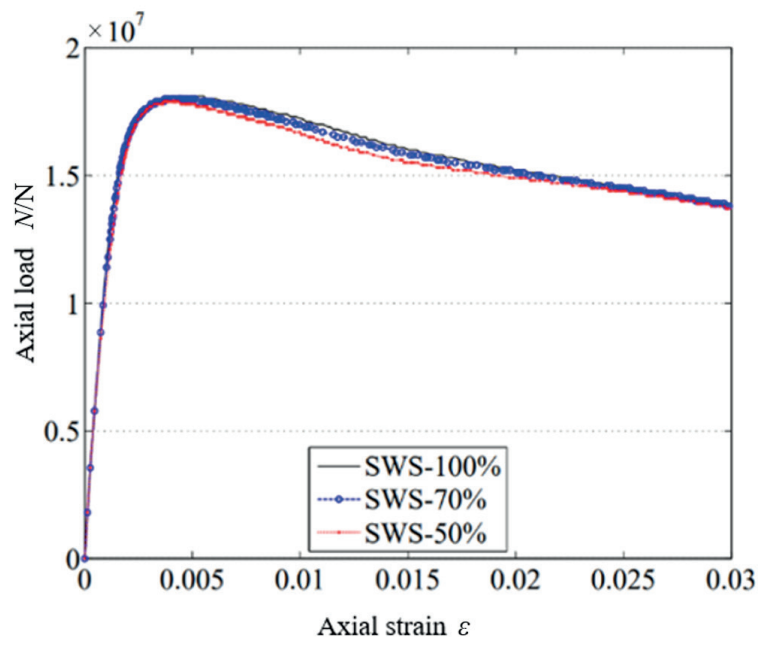

(b)

Fig. 9 Comparison of $N$ versus $\varepsilon$ relations, (a) EST, (b) CFST

while the SWS-S is far lower than the base metal, the instability failure occurs in the middle of the pipe along the SWS, which indicates that the SWS-S has an important influence on the static stability of EST.

\subsubsection{Characteristic destroyed modes in the presence or absence of SWS defect}

The fracture modes of the core concrete column in the CFST rib and the characteristic SWT-S are compared in Figs. 11-12.

As evident in Fig. 11, where the SWT-S is different from that of parent material, the stress distribution of each part of the steel pipe is uneven under eccentric axial-load, but the yield strength of each part of the steel pipe also reaches the peak point, same as the parent material.

It depicts that the SWTs strength belonging to the CFST reduced at the SWS; nevertheless, it was not the same as the modes of EST failure with localized fold buckling. 


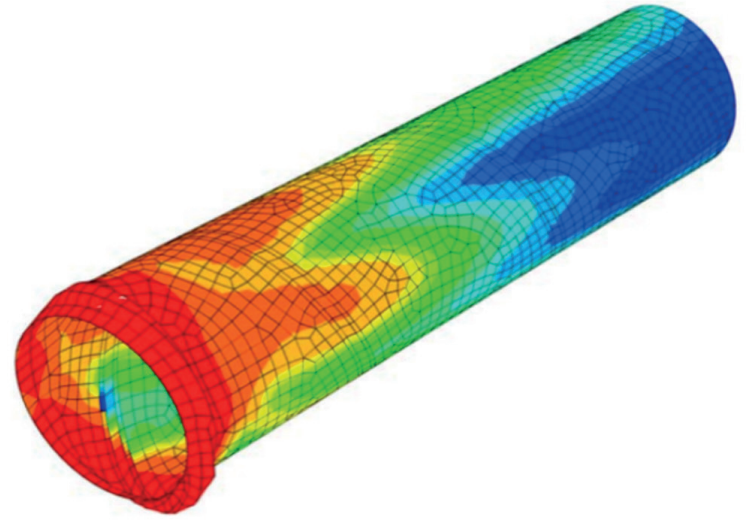

(a)

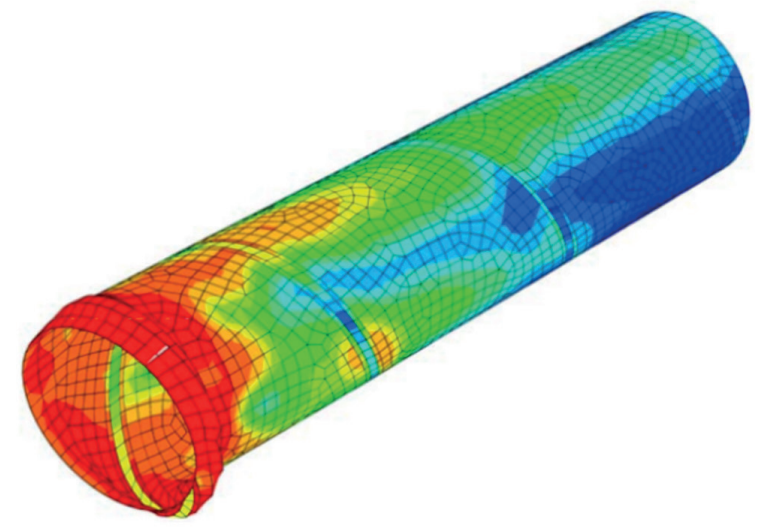

(b)

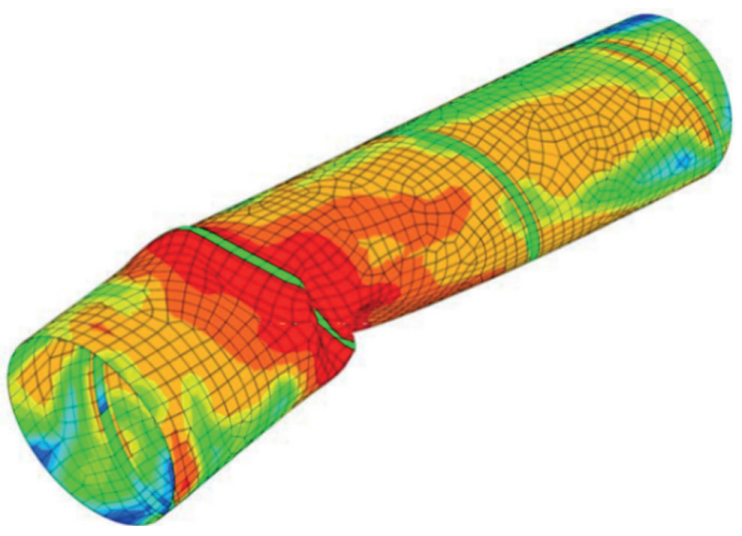

(c)

Fig. 10 EST Mises stresses with different SWS-S, (a) SWS: $100 \%$, (b) SWS: $70 \%$, (c) SWS: $50 \%$

Besides, a high potential for the confinement of the core concrete was manifested, and the core concrete prevented local bucking by providing firm support to the outer SWT. Subsequently, it was ensured that the concrete and steel tube function together to attain the desired output.

The Mises stresses of the CFST concrete core encountering various SWS-S are presented in Fig. 12. According to the findings, the SWTs or core concrete carries the same stresses (Mises) and an approximately similar CFST

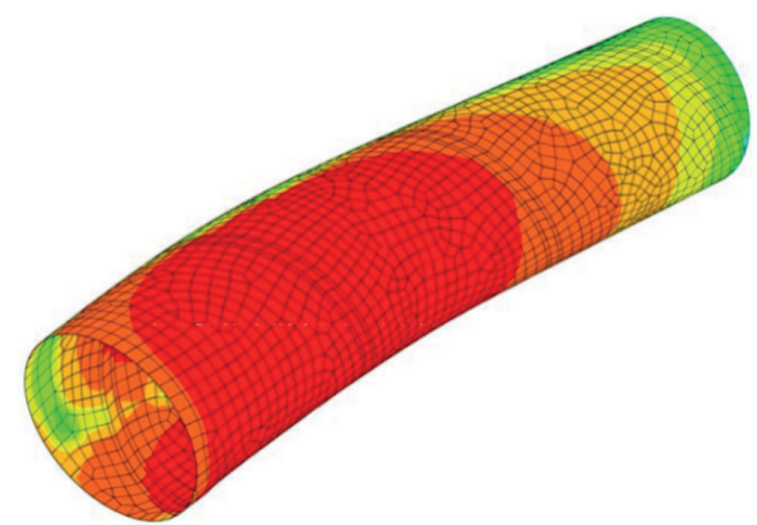

(a)

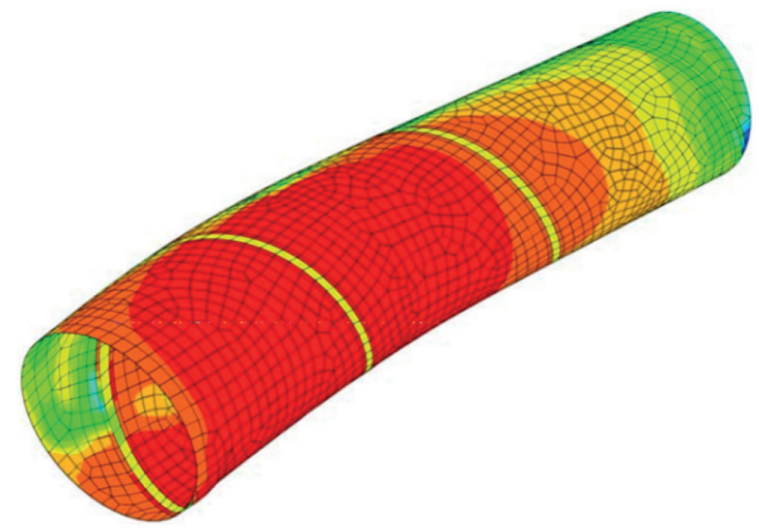

(b)

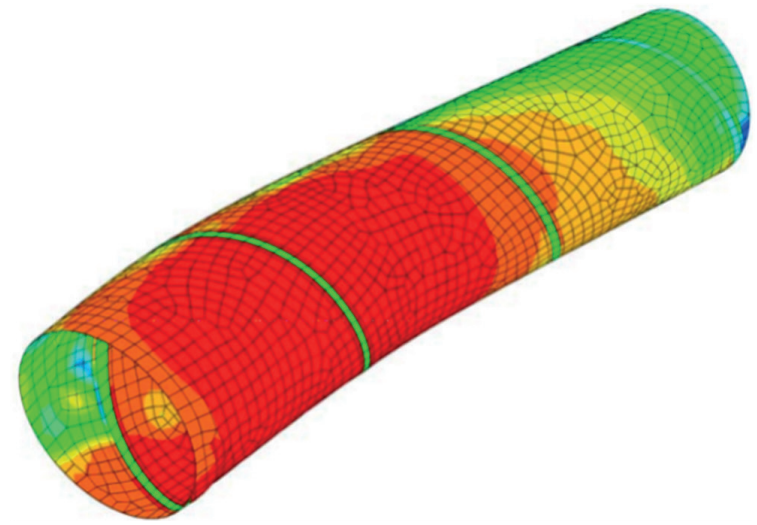

(c)

Fig. 11 Tube Mises stresses in CFST with different SWS-S, (a) Tube SWS: $100 \%$, (b) Tube SWS: $70 \%$, (c) Tube SWS: $50 \%$

deformation was manifested by the ribs in the presence or absence of an SWS-S fault. This took place despite SWS leading to a $30 \%$ to $50 \%$ loss in the strength of the SWTs belt in this particular case due to faults in the weld seam.

As a matter of fact, the decline in the strength of CFST rib having a defect of SWS-S was not clear under circumstances when the core concrete was accumulated. Also, it could be ascertained that the SWS strength having defects became lessened in the weld zone. 


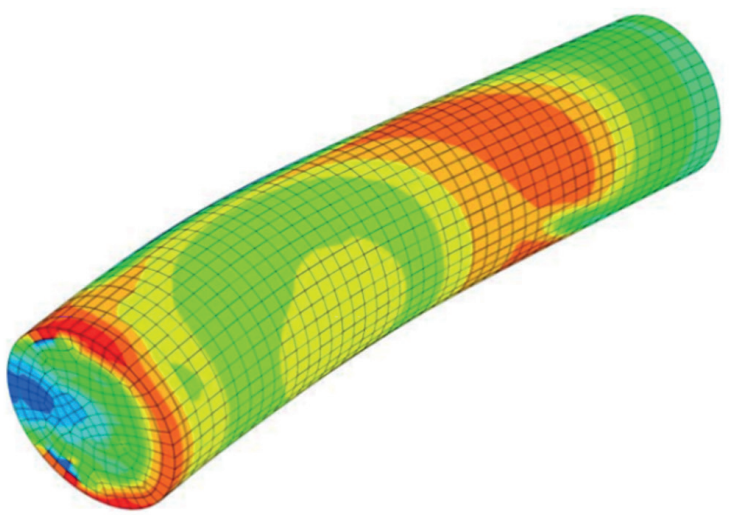

(a)

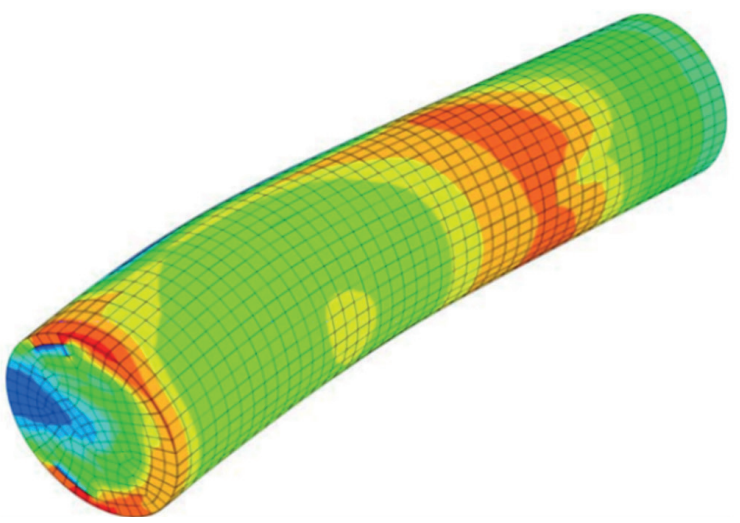

(b)

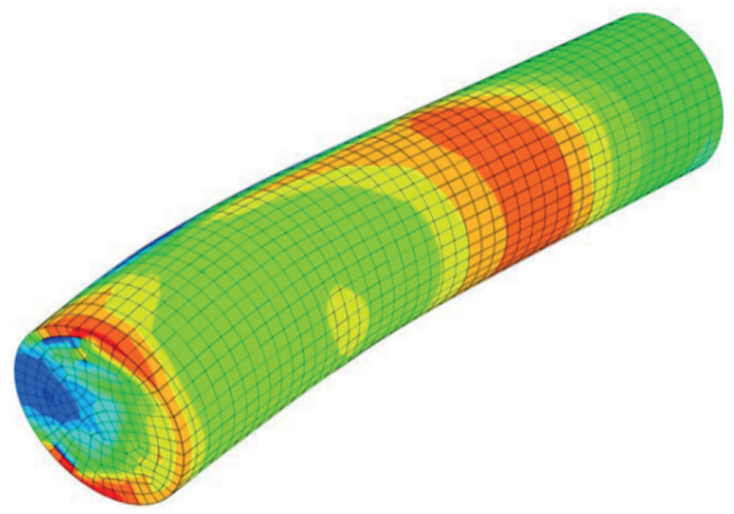

(c)

Fig. 12 Concrete Mises stresses in CFST with different SWS-S, (a) Concrete SWS: $100 \%$, (b) Concrete SWS: $70 \%$, (c) Concrete SWS: $50 \%$

\subsection{Analyzing the CFST arch rib having a defect of air-void}

\subsection{1 $\mathrm{N}-\varepsilon$ curves with defect of air-void}

The curves of $N-\varepsilon$ corresponding to the CFST rib with or without various rates of air-void ( $\alpha=10 \%, 20 \%$, and $30 \%$ ) are compared in Fig. 13 compares. It is evident from Fig. 13 that whether or not there were air-voids, the CFST manifested characteristic strain-softening attributes, which is in complete agreement with the outcomes reported by Gunawardena and Aslani [2], and Gunawardena et al. [3].

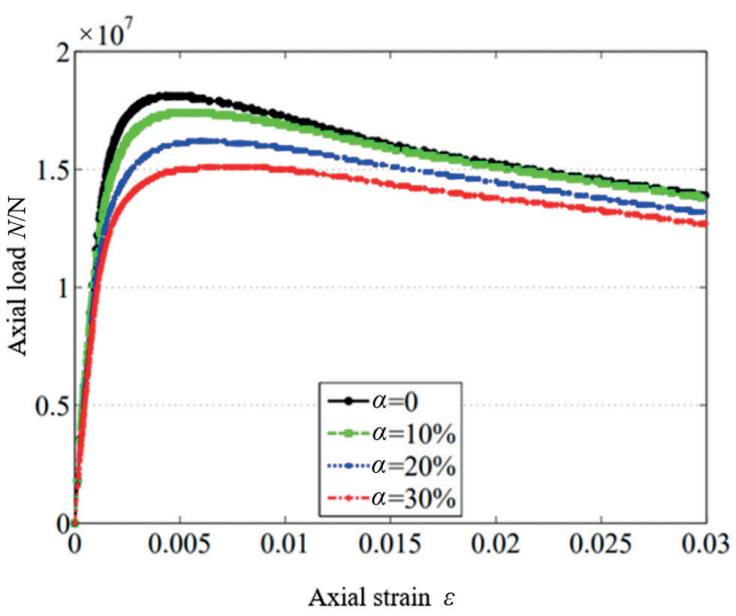

Fig. 13 Comparison of $N-\varepsilon$ relations

The strain-softening and yield took place when airvoid remained in the CFST rib, which again corroborates with the outcomes of Han et al. [22], Liu et al. [24] and Liao et al. $[25,26]$. The $N-\varepsilon$ curves under the circumstances of individual air-void ratios are depicted individually in Fig. 13 to have a better examination of the impact of the air-void rates on the capacity of bearing related to the CFST. A single point of yield at various $\alpha$ conforming to the curves of $N-\varepsilon$ when the peak load was achieved, corresponds to the stage when the strain-softens. The value of $N$ of the rib having air-voids underwent a sudden decrease after the peak load as evident in Fig. 13 whereas at $\alpha=10 \%$ to $30 \%$ or without any air-void faults the $N-\varepsilon$ curves of the rib manifest a rather smoother form. Later, in the absence of any defect of air-void, the highest value of $N-\varepsilon$ curves approaches a maximum of $18.1 \times 10^{6} \mathrm{~N}$; the highest value of $N-\varepsilon$ curves falls to $17.4 \times 10^{6} N$ at $\alpha=10 \%$; while the highest value of $N-\varepsilon$ curve falls to $15.1 \times 10^{6} \mathrm{~N}$ at $\alpha=30 \%$, which is $16.6 \%$ low in comparison to the sound condition.

\subsubsection{Characteristic destroyed modes in the presence of an air-void defect}

The characteristic devastated modes of the CFST rib are juxtaposed in Fig. 14. In an attempt to put forth a clear illustration of the deformed appearance of the columns, a two-fold amplification of the elephant foot-shaped buckling deformation has been shown. These deformations were located around the center of the CFST stub column. It is noteworthy that, the wall enclosing the tube is nearly even having no localized buckling for the CFST with $\alpha=10 \%$. However, at $\alpha=20 \%$, only one buckling deformity with an elephant foot-shape can be seen to take place, while for the CFST with $\alpha=30 \%$, there was a series 
of foot-shaped buckling deformations, thus implying that a bigger air-void led to the creation of a substantial space for localized buckling misshaping in the steel tube.

The destroyed modes of CFST with various air-void ratio show that the failure modes of the SWTs are different from the modes when the concrete core column is perfect, and also different from that of the EST. This shows that whether or not the interplay among steel tube and concrete, directly influences the instability mode of SWTs, which makes the unified theory of bearing capacity calculation of CFST based on ideal state encountered difficulties.

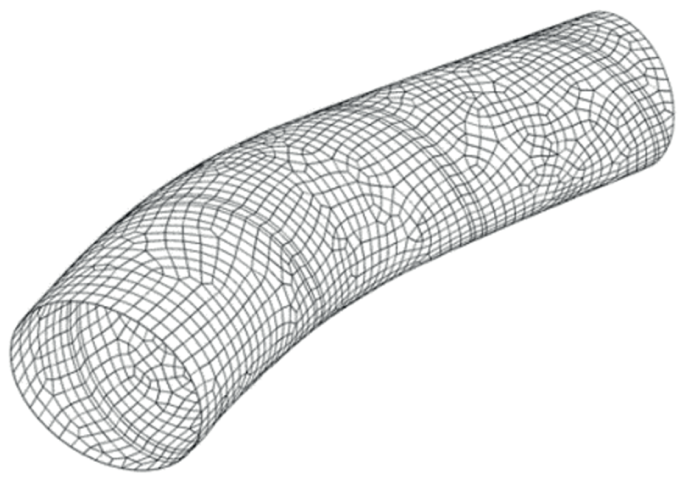

(a)

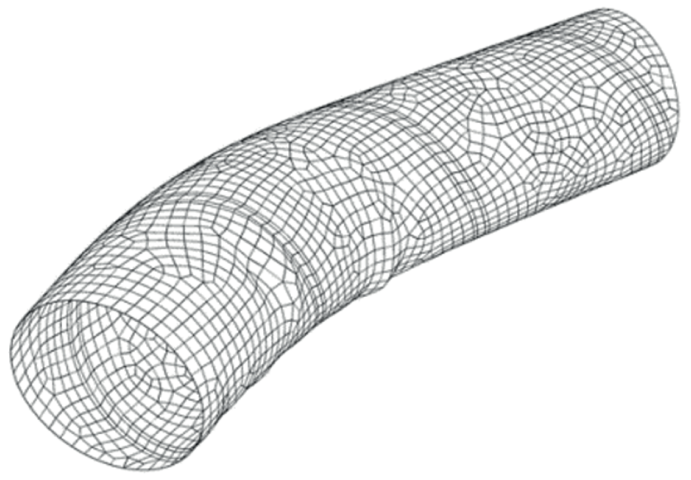

(b)

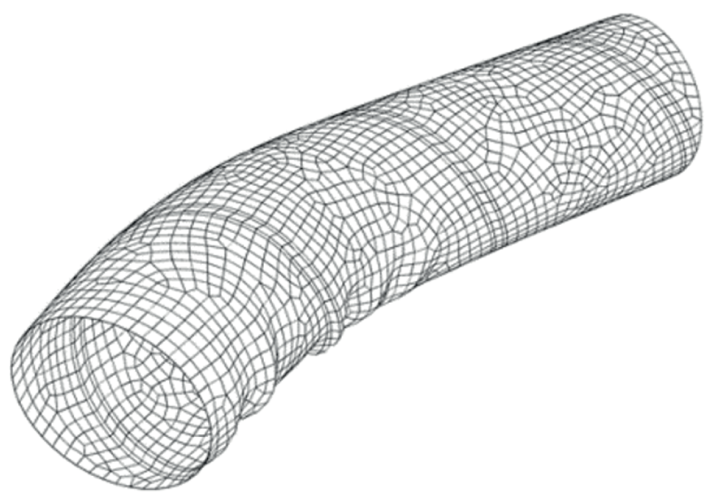

(c)

Fig. 14 Destroyed modes of CFST with different $\alpha$, (a) $\alpha=10 \%$, (b)

$$
\alpha=20 \% \text {,(c) } \alpha=30 \%
$$

The malformed figures of the concrete core at $70 \mathrm{~mm}$ thick cylindrical region with different air-void rates are depicted in Fig. 15. The concrete manifested various bending deformation modes at different air-void rates. It is observable that the stress state of concrete transforms from being uniformly distributed to being entirely concentrated on the core area, with the increase of $\alpha$, which is practically equivalent to the decrease of diameter. When the ratio of air-void was not considerable, the bending deformation of concrete was relatively close to what could have taken place under the influence of a full restraint, as depicted in Fig. 15.

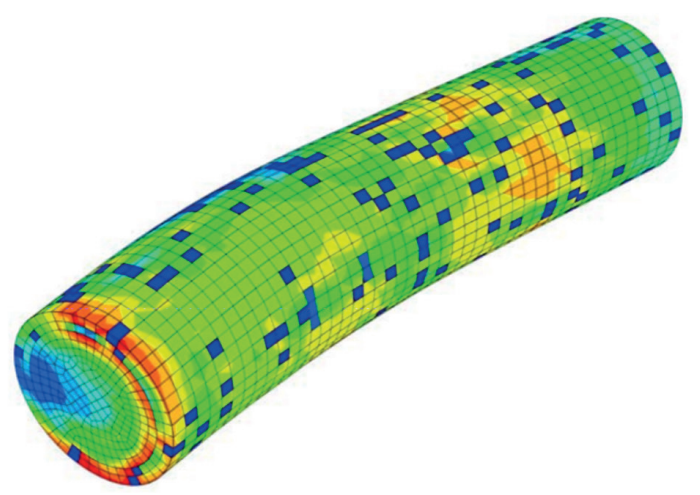

(a)

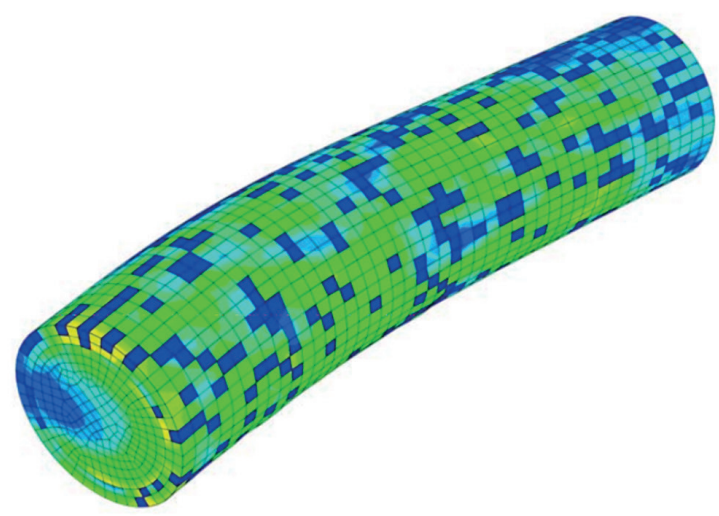

(b)

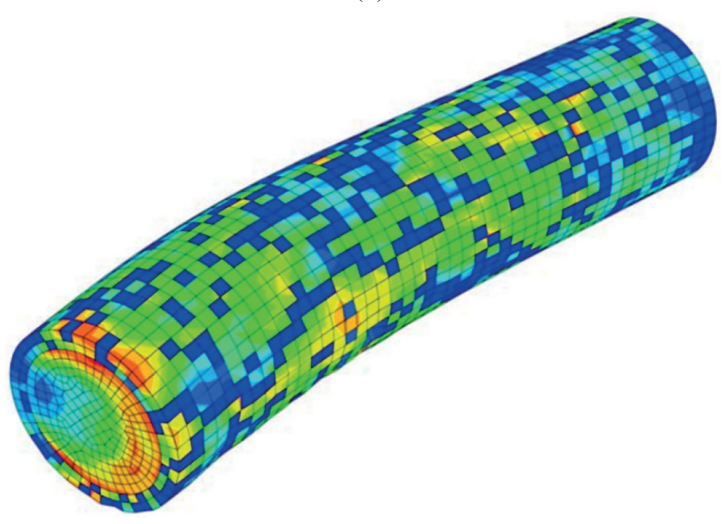

(c)

Fig. 15 Concrete Mises stresses in CFST with different air-void rates, (a) $\alpha=10 \%$, (b) $\alpha=20 \%$, (c) $\alpha=30 \%$ 
Stress and bending deformation become exceedingly concentrated in the central zone with the increment in the rate of air-void, practically resulting in a brittle failure and local fracture stage manifested by the CFST. It is evident that, with the further enhancement within the ratio of airvoid, a large cross-section malformation within the concrete took place in the middle. Thereafter, once the concrete air void was packed, the cross-section deformation of the concrete at the origin was once again limited via the SWTs. As a consequence, the fractured site of the concrete showed a tendency of movement towards the rib mid-height. In the portions where the SWTs localized deformation took place, failure of the concrete was seen, as indicated in Fig. 14.

\section{Composite strength index}

The entire analysis shows that the net impact of the degree of SWS on the bearing capacity of CFST differs substantially as compared to the concrete core, and the influence of weld seam, in turn, relies upon the effects of the concrete defect, Hence, the concrete air-void is the decisive defect of CFST. For quantitative evaluation of the extent to which CFST bearing capacity is influenced by the air-void rates, a strength criterion SI is given through the following expression:

$S I=\frac{N_{a-d e f}}{N_{n-d e f}}$

$N_{n \text {-def }}$ is the maximal value of the CFST rib $N-\varepsilon$-curves with no defects whereas is the maximal value of the CFST rib $N-\varepsilon-$ curves with air-void defects. Fig. 16 presents the values matrix of SI for the CFST ribs having various air-voids. As per the experience data in the reports of Liao et al. [26], a reduction in the cross-type circumferential gap to a value of $0.05 \%$, the resultant loss in the strength of the CFST rib is well under $5 \%$. When the decline in the SWS strength is not taken into consideration while defining SI of the CFST, it agrees quite closely to the outcomes reported by Ellobody and Young [9], Hassanein [14] and Dai and Lam [17]. However, in realtime, this bridge does not a have cross-type air-void and is much larger than the mentioned experimental level, thereby implying that the area covered by the FEM determined results was relatively large. In addition, the SI values went through a rapid decline from 1 to 0.835 with the increase in $\alpha$ from 0 to 0.3 . Therefore, the relationship between SI and $\alpha$ was established as indicated in Fig. 16, using a multiple linear regression method outlined below:
$S I=1-\alpha\left(1-e^{b \alpha}\right)$

Following are the coefficients (with $95 \%$ confidence bounds): $a=-0.2144$ ( $-0.7586,0.3298), b=1.917$ ( -1.892 , 5.727). Determination of the goodness of fit was carried out in the following manner follows SSE: 6.772e-05, R-square: 0.9958, modified R-square: 0.9937, and RMSE: 0.005819 . The significance of $\alpha$ on SI was considerably high as determined from Eq. (21). Additionally, the CFST ribs are significantly influenced by the air-void in terms of the bearing capacity, destroyed mode, and corresponding deformation.

\section{Conclusions}

This work is based on the collection of empirical field data based on ultrasonic scanning related to the bridge constructed on Chang-Qing Hun River. The gathered data has been utilized to create a compound FEM for the simulation of the arch rib of the CFST bridge under the influence of eccentric axial compression. The existing FEM and CFST indoor experiments put forth by Tao et al. [15], Han et al. [22] and Liao et al. [26], were contrasted with the calculated version. In [22], particularly in terms of the reliability of prediction. The interpretations elaborated below are the primary outcomes of this study:

(1) Quite a few reasonable predictions can be made by the FEMs and various investigations performed through Han et al. [22], Liao et al. [26], and Tao et al. [15], for a small circumferential gap, normal, or cap-gap defect, of the columns of CFST; Nevertheless, these predictions understate the notable impact of arbitrary air-void within the core of concrete on the subsequent toughness of circular truss element ribs for CFST in usage for an extended duration and rather rough settings within the systems of arch bridge.

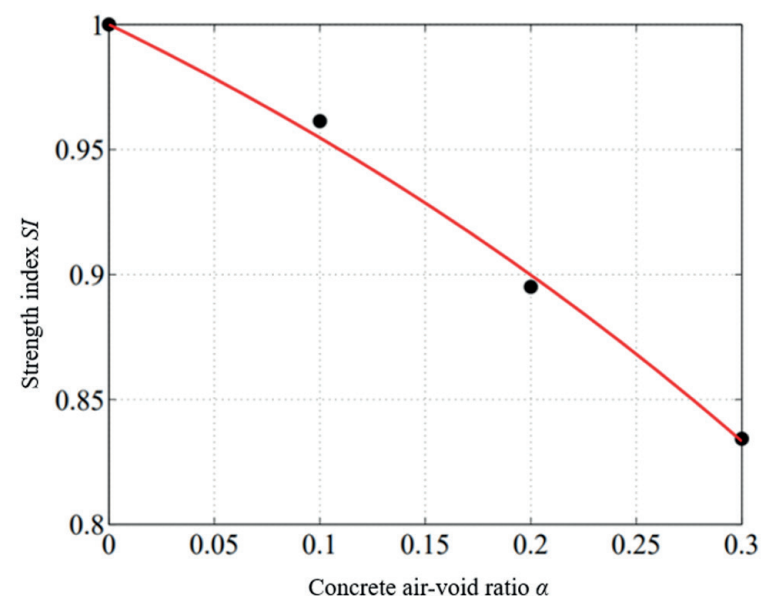

Fig. 16 Influence of $\alpha$ on SI 
(2) During this investigation, a group of FEMs was created for the truss rib of the CFST arch bridge, wherein the field ultrasonic inspection test data was employed to calibrate the defect of the air-void in the core concrete shaft. Simultaneously, we obtained the strain-softening/ hardening and yielding rules related to the curves of peakpost corresponding to CFST for localized deformation in the steel tube accompanied by different SWS strength. Another important finding included CFST bearing capacity being only minimally affected by weld strength.

(3) For the group of FEM results, the strength index SI corresponding to the CFST having a defect of air-void was outlined anew. A comparison was drawn between the projected outcomes making use of the new index and the

\section{References}

[1] Zheng, J., Wang, J. "Concrete-Filled Steel Tube Arch Bridges in China", Engineering, 4(1), pp. 143-155, 2018. https://doi.org/10.1016/j.eng.2017.12.003

[2] Gunawardena, Y., Aslani, F. "Behaviour and design of concrete-filled mild-steel spiral welded tube short columns under eccentric axial compression loading", Journal of Constructional Steel Research, 151, pp. 146-173, 2018. https://doi.org/10.1016/j.jcsr.2018.09.018

[3] Gunawardena, Y., Aslani, F., Li, J., Hao, H. "In Situ Data Analysis for Condition Assessment of an Existing Prestressed Concrete Bridge", Journal of Aerospace Engineering, 31(6), Article No. 04018106, 2018.

https://doi.org/10.1061/(asce)as.1943-5525.0000935

[4] Sovannsathya, R., Ouchi, M., Puthipad, N., Attachaiyawuth, A. "Improving the stability of entrained air in self-compacting concrete by optimizing the mix viscosity and air entraining agent dosage", Construction and Building Materials, 148, pp. 531-537, 2017. https://doi.org/10.1016/j.conbuildmat.2017.05.105

[5] Ye, F., Zha, X., Wang, H. "The application of a HHT based ultrasonic detecting method in quality assessment of CFST", Advanced Steel Construction, 7(2), pp. 182-191, 2011.

https://doi.org/10.18057/IJASC.2011.7.2.5

[6] Liu, H., Xia, H., Zhuang, M., Long, Z., Liu, C., Cui, J., Xu, B., $\mathrm{Hu}$, Q., Liu, Q. H. "Reverse time migration of acoustic waves for imaging based defects detection for concrete and CFST structures", Mechanical Systems and Signal Processing, 117, pp. 210-220, 2019. https://doi.org/10.1016/j.ymssp.2018.07.011

[7] Yan, S., Zhang, B., Song, G., Lin, J. "PZT-Based Ultrasonic Guided Wave Frequency Dispersion Characteristics of Tubular Structures for Different Interfacial Boundaries", Sensors, 18(12), Article No. 4111, 2018.

https://doi.org/10.3390/s18124111

[8] Dong, W., Wu, Z., Zhou, X., Tan, Y. "Experimental studies on void detection in concrete-filled steel tubes using ultrasound", Construction and Building Materials, 128, pp. 154-162, 2016. https://doi.org/10.1016/j.conbuildmat.2016.10.061 collected test data, suggesting that the new index has a better versatility as well as accuracy in terms of calculations of bearing capacity of CFST ribs for the air-void fault in the concrete core. It is illustrated quantitatively by the novel criterion SI expression that CFST bearing capacity is notably influenced by $\alpha$. Therefore, the chief characteristic that needs to certify the capacity of bearing within the CFST arch bridge is decreasing the air-void in the core of concrete.

\section{Acknowledgement}

The project presented in this article is supported by Plan of Liaoning Province to revitalize Liaoning talents (No. XLYC1907121), and Scientific Research Project of Liaoning Provincial Department of Education (No. lnjc202019).

[9] Ellobody, E., Young, B. "Nonlinear analysis of concrete-filled steel SHS and RHS columns", Thin-Walled Structures, 44(8), pp. 919930, 2006.

https://doi.org/10.1016/j.tws.2006.07.005

[10] Han, L.-H., Yao, G.-H., Tao, Z. "Performance of concrete-filled thin-walled steel tubes under pure torsion", Thin-Walled Structures, 45(1), pp. 24-36, 2007. https://doi.org/10.1016/j.tws.2007.01.008

[11] Schneider, S. P. "Axially Loaded Concrete-Filled Steel Tubes", Journal of Structural Engineering, 124(10), pp. 1125-1138, 1998. https://doi.org/10.1061/(ASCE)0733-9445(1998)124:10(1125)

[12] Hu, H.-T., Huang, C.-S., Wu, M.-H., Wu, Y.-M. "Nonlinear Analysis of Axially Loaded Concrete-Filled Tube Columns with Confinement Effect", Journal of Structural Engineering, 129(10), pp. 1322-1329, 2003.

https://doi.org/10.1061/(ASCE)0733-9445(2003)129:10(1322)

[13] Ellobody, E., Young, B. "Design and behaviour of concrete-filled cold-formed stainless steel tube columns", Engineering Structures, 28(5), pp. 716-728, 2006.

https://doi.org/10.1016/j.engstruct.2005.09.023

[14] Hassanein, M. F. "Numerical modeling of concrete-filled lean duplex slender stainless steel tubular stub columns", Journal of Constructional Steel Research, 66(8-9), pp. 1057-1068, 2010. https://doi.org/10.1016/j.jcsr.2010.03.008

[15] Tao, Z., Uy, B., Liao, F.-Y., Han, L.-H. "Nonlinear analysis of concrete-filled square stainless steel stub columns under axial compression", Journal of Constructional Steel Research, 67(11), pp. 17191732, 2011. https://doi.org/10.1016/j.jcsr.2011.04.012

[16] Tao, Z., Uy, B., Han, L.-H., Wang, Z.-B. "Analysis and design of concrete-filled stiffened thin-walled steel tubular columns under axial compression", Thin-Walled Structures, 47(12), pp. 1544-1556, 2009. https://doi.org/10.1016/j.tws.2009.05.006

[17] Dai, X., Lam, D. "Numerical modelling of the axial compressive behaviour of short concrete-filled elliptical steel columns", Journal of Constructional Steel Research, 66(7), pp. 931-942, 2010. https://doi.org/10.1016/j.jcsr.2010.02.003 
[18] Hu, H.-T., Su, F.-C. "Nonlinear analysis of short concrete-filled double skin tube columns subjected to axial compressive forces", Marine Structures, 24(4), pp. 319-337, 2011. https://doi.org/10.1016/j.marstruc.2011.05.001

[19] Huang, H., Han, L.-H., Tao, Z., Zhao, X.-L. "Analytical behaviour of concrete-filled double skin steel tubular (CFDST) stub columns", Journal of Constructional Steel Research, 66(4), pp. 542-555, 2010. https://doi.org/10.1016/j.jcsr.2009.09.014

[20] Jaishi, B., Ren, W.-X. "Structural Finite Element Model Updating Using Ambient Vibration Test Results", Journal of Structural Engineering, 131(4), pp. 617-628, 2005. https://doi.org/10.1061/(ASCE)0733-9445(2005)131:4(617)

[21] Han, L.-H., Hou, C.-C., Wang, Q.-L. "Behavior of circular CFST stub columns under sustained load and chloride corrosion", Journal of Constructional Steel Research, 103, pp. 23-26, 2014. https://doi.org/10.1016/j.jcsr.2014.07.021

[22] Han, L.-H., Ye, Y., Liao, F.-Y. "Effects of core concrete initial imperfection on performance of eccentrically loaded CFST columns", Journal of Structural Engineering, 142(12), Article No. 04016132, 2016.

https://doi.org/10.1061/(ASCE)ST.1943-541X.0001604

[23] Huang, Y.-H., Liu, A.-R., Fu, J.-Y., Pi, Y.-L. "Experimental investigation of the flexural behavior of CFST trusses with interfacial imperfection", Journal of Constructional Steel Research, 137, pp. 52-65, 2017.

https://doi.org/10.1016/j.jcsr.2017.06.009

[24] Liu, X., Sun, Z., Tang, S., Huang, H., Liu, A. "A new calculation method for axial load capacity of separated concrete-filled steel tubes based on limit equilibrium theory", Journal of Central South University, 20(6), pp. 1750-1758, 2013.

https://doi.org/10.1007/s11771-013-1668-7

[25] Liao, F.-Y., Han, L.-H., He, S.-H. "Behavior of CFST short column and beam with initial concrete imperfection: Experiments", Journal of Constructional Steel Research, 67(12), pp. 1922-1935, 2011. https://doi.org/10.1016/j.jcsr.2011.06.009

[26] Liao, F.-Y., Han, L.-H., Tao, Z. "Behavior of CFST stub columns with initial concrete imperfection: Analysis and calculations", ThinWalled Structures, 70, pp. 57-69, 2013. https://doi.org/10.1016/j.tws.2013.04.012

[27] Han, L.-H., Yao, G.-H., Tao, Z. "Performance of concrete-filled thin-walled steel tubes under pure torsion", Thin-Walled Structures, 45(1), pp. 24-36, 2007.

https://doi.org/10.1016/j.tws.2007.01.008
[28] Tao, Z., Wang, Z.-B., Yu, Q. "Finite element modelling of concrete-filled steel stub columns under axial compression", Journal of Constructional Steel Research, 89, pp. 121-131, 2013. https://doi.org/10.1016/j.jesr.2013.07.001

[29] Tao, Z., Wang, X.-Q., Uy, B. "Stress-Strain Curves of Structural and Reinforcing Steels after Exposure to Elevated Temperatures", Journal of Material Civil Engineering, 25(9), pp. 1306-1315, 2013. https://doi.org/10.1061/(ASCE)MT.1943-5533.0000676

[30] ACI Committee 318 "Building Code Requirements for Structural Concrete (ACI 318-11) and Commentary", American Concrete Institute, Farmington Hills, MI, USA, 2011.

[31] Papanikolaou, V. K., Kappos, A. J. "Confinement-sensitive plasticity constitutive model for concrete in triaxial compression", International Journal of Solids and Structures, 44(21), pp. 7021-7048, 2007. https://doi.org/10.1016/j.ijsolstr.2007.03.022

[32] Mander, J. B., Priestley, M. J. N., Park, R. "Theoretical Stress-Strain Model for Confined Concrete", Journal of Structural Engineering, 114(8), pp. 1804-1826, 1988. https://doi.org/10.1061/(ASCE)0733-9445(1988)114:8(1804)

[33] Mander, J. B., Priestley, M. J. N., Park, R. "Observed Stress-Strain Behavior of Confined Concrete", Journal of Structural Engineering, 114(8), pp. 1827-1849, 1988. https://doi.org/10.1061/(ASCE)0733-9445(1988)114:8(1827)

[34] Han, L.-H., An, Y.-F. "Performance of concrete-encased CFST stub columns under axial compression", Journal of Constructional Steel Research, 93, pp. 62-76, 2014. https://doi.org/10.1016/j.jcsr.2013.10.019

[35] Liao, F.-Y., Han, L.-H., Tao, Z. "Performance of reinforced concrete shear walls with steel reinforced concrete boundary column", Engineering Structures, 44, pp. 186-209, 2012. https://doi.org/10.1016/j.engstruct.2012.05.037

[36] Samani, A. K., Attard, M. M. "A stress-strain model for uniaxial and confined concrete under compression", Engineering Structures, 41, pp. 335-349, 2012. https://doi.org/10.1016/j.engstruct.2012.03.027

[37] Yu, T., Teng, J. G., Wong, Y. L., Dong, S. L. "Finite element modeling of confined concrete-I: Drucker-Prager type plasticity model", Engineering Structures, 32(3), pp. 665-679, 2010. https://doi.org/10.1016/j.engstruct.2009.11.014

[38] Yu, T., Teng, J. G., Wong, Y. L., Dong, S. L. "Finite element modeling of confined concrete-II: Plastic-damage model", Engineering Structures, 32(3), pp. 680-691, 2010. https://doi.org/10.1016/j.engstruct.2009.11.013 